\title{
Cropping Mulberry (Morus alba) in the Drawdown Zone of the Three Gorges Reservoir
}

\author{
Yun Liu $1^{*}$, J.H. Martin Willison ${ }^{2}$ \\ ${ }^{1}$ Key Laboratory of the Three Gorges Reservoir Region's Eco-Environment (Southwest University), Ministry of \\ Education, College of Resources and Environment, Southwest University, Chongqing 400716, China \\ ${ }^{2}$ School for Resource and Environmental Studies, Dalhousie University, Halifax, Nova Scotia, Canada B3H 4R2 \\ Email: utrecht@swu.edu.cn
}

\begin{abstract}
The drawdown zone of China's Three Gorges Reservoir is available for crops during summer, but few perennial crops tolerate the winter flooding stress. We examined white mulberry (Morus alba L.) at a site in Muhe Village, Chongqing, where a 15-yearold mulberry plantation has survived seven cycles of winter immersion since 2009. The plantation lies on riverside terraces and is maintained by silk farmers who have adapted their crop management regime for the changed conditions. Despite benefits to farmers, their use of the resource conflicts with the management regime for the reservoir, which had not anticipated mulberry survival. It is concluded that mulberry trees have potential roles in a strategy for managing the drawdown zone so as to provide environmental protection, ecosystem services and use of the land resource. It is recommended that the reservoir management system become more adaptive and participatory, and that land-use regulations encourage mulberry use.
\end{abstract}

Keywords: Sericulture, Morus alba, Three Gorges Reservoir, flooding stress, ecosystem services

\section{Introduction}

Perennial vegetation provides many environmental benefits on the banks surrounding reservoirs, such as reduced input of sediments, sequestration of soluble nutrients, and shade [1]. In densely-populated developing countries there is also strong demand that environmental benefits be matched with agricultural benefits [2]. While it is relatively easy to obtain both environmental and agricultural benefits above the high water line on the banks of a reservoir, it is difficult in the zone subjected to periodic flooding. Here we describe a white mulberry (Morus alba L.) plantation that grows in the drawdown zone of the Three Gorges Reservoir (TGR) in China and provides valuable harvests for some small-scale farmers who live beside the reservoir. This unusual case is unfolding instructively in a situation that is ecologically and socially complex.

China's Three Gorges Dam on the Changjiang (Yangtze River) provides the benefits of flood control, electrical power generation, and ease of river transportation, but with environmental, social and economic costs [3], [4], [5]. Much attention has been paid to the environmental risks and associated mitigations related to the TGR [3], [4], [6], and recently there has been growing interest in restoring ecosystem functions and services to its riparian zone [7], [8], [9], [10], [11].

The Changjiang basin is subjected to heavy summer monsoon rains which have historically produced severe floods in the lower reaches of the river [4], [6]. To overcome this problem, the water level in the TGR is lowered during summer to $30 \mathrm{~m}$ below its optimal level for electrical power generation in preparation for flood control (Fig. 1). When a flood pulse arrives, it is attenuated by short-term storage of water in the reservoir and the stored water is subsequently released at a controlled rate calculated to avoid catastrophic damage downstream. Lowering the water in this way during summer creates a reservoir drawdown zone of about $350 \mathrm{~km}^{2}$ around the edge of the reservoir [6], [12]. The reservoir itself lies within a mountainous region and is confined to the steep-sided valleys of the main river and its many tributaries, and so the drawdown zone consists of a ribbon of sloping land which averages about $70 \mathrm{~m}$ in breadth and $4900 \mathrm{~km}$ in total ribbon length [8].

Based on surveys and experiments, Yang et al. [10] recently recommended 6 tree species as suitable for restoration of riparian woodland in the upper 170-175m component of the TGR drawdown zone, of 
which two (Populus $x$ canadensis and $M$. alba) were particularly good candidates because they recover adaptively from flooding stress. About 14 species of native trees and shrubs have been observed to survive deep flooding in the TGR, with progressive mortality [10], [13], but most of these species have little or no value for farmers. $M$. alba is exceptional in that it is agriculturally valuable. Survival of $M$. alba after several months of immersion in the TGR was first described by He et al. [14] following the winter impoundment cycle of 2006/7. M. alba is a native tree that has been cropped in China for millennia (for review, see [15]). It provides many values for local farming economies: leaves for silk production (sericulture) and animal forage, woody stems for mushroom cultivation, root bark for traditional medicine, and fruit. Silkworms are raised by the individual mulberry farmers themselves.

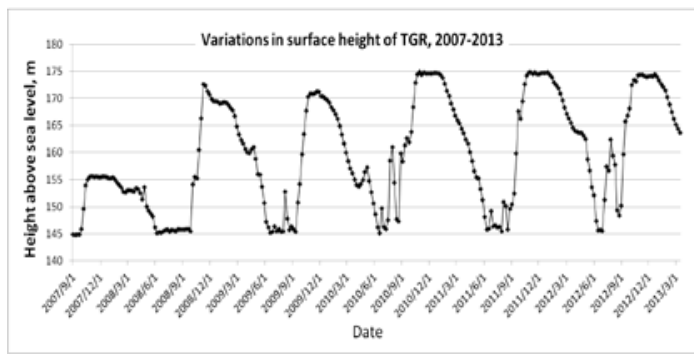

Figure 1. A hydrograph of weekly points showing changes in the height of the water surface in the TGR at the TGD from 01-09-2007 to 16-03-2013. From 2010 to 2016 the water has been drawn down annually in summer to about $145 \mathrm{~m}$ from the winter height of about $175 \mathrm{~m}$, and this pattern is planned to be continued in the future. The upper $7-8 \mathrm{~m}$ of the reservoir drawdown zone containing the mulberry plantation was partially flooded from midOctober to mid-February (approximately 4 months) in 2008 and 2009, and fully flooded during winters in the period 2010-2013. The plantation was not affected by the strong flood pulses due to monsoon rains in July/August 2010 and 2012. Figure prepared by Xingzheng Xiong using data from the China Three Gorges Corporation available at: http://www.ctgpc.com.cn/inc /sqsk.php.

\section{$2 \quad$ Site Description and Observations}

\subsection{Mulberry Plantation}

A mulberry plantation, lying at $29^{\circ} 51^{\prime} \mathrm{N}, 107^{\circ} 28^{\prime} \mathrm{E}$, was established by sericulture farmers at Muhe village (Fig. 2) in Fuling County, Chongqing Municipality, in the mid-1990s. The soil is a clay-rich 'purple soil' which is common in the region. Following several years of normal use, most of the plantation was flooded in the winter of $2008 / 9$ as a result of the creation of the Three Gorges Reservoir. In 2009 the farmers notified the lead author that the trees had survived and investigation of the case was begun by making field observations, including discussions with the farmers.

Sericulture is common in the region surrounding Muhe village and the farmers' practices prior to the creation of the reservoir were typical for the region. A variety of $M$. alba of local origin that has been used by local farmers for generations provided the rootstocks. After about a year of growth of the rootstocks, buds obtained from the Jialing No. 20 variety were grafted onto the main stems of the rootstocks at about $15-20 \mathrm{~cm}$ above the soil surface. Three buds per stem are normally grafted. Rootstock stems above the graft unions were later pruned away. In December (winter), following one season of growth, the grafted scions were pruned at about $1 \mathrm{~m}$ above the soil surface to create short pollards consisting of 1-3 graft stems of a convenient height for future use. The plantation consisted of hundreds of pollards set on a series of terraces at about 165 to $178 \mathrm{~m}$ above sea level. $M$. alba is dioecious but for sericulture the sex of individual trees is considered unimportant, therefore male and female scions were mixed arbitrarily in the plantation. 


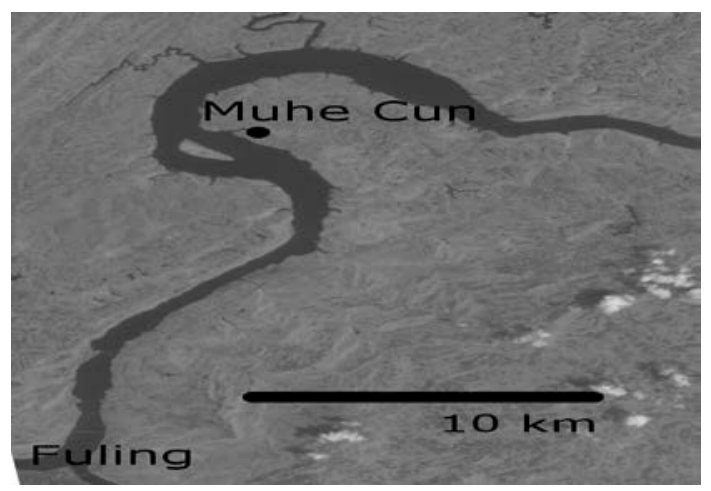

Figure 2. Location of Muhe village (Muhe Cun), and Fuling town in Fuling County, Chongqing Municipality, relative to a small portion of the TGR (April 10, 2013). Modified from an infrared NASA image in the public domain.

Following establishment, the plantation was maintained conventionally for several years (Fig. 3) until its management was altered after impoundment of the reservoir (Fig. 4). Branches sprout from the pollards in spring and leaves are harvested continuously as the branches elongate through summer (Fig. 3 ), eventually reaching up to $3 \mathrm{~m}$ in length. M. alba is deciduous and leaves begin to fall in November, by which time the silkworms are also dormant. Most of the leaves on the sprouted branches have been harvested for sericulture by the time of leaf fall, and so in October branches have only a few remnant leaves at their tips. In December the branches are all pruned away to their bases, thereby returning the tree to a short pollard again (Fig. 3). At time of pruning, the tree has the form of a bush with 20 or more branches per tree that are 1-3 m tall, rising vertically from the head of the stump. Pruned branches have several uses, such as for firewood and for growing edible mushrooms.

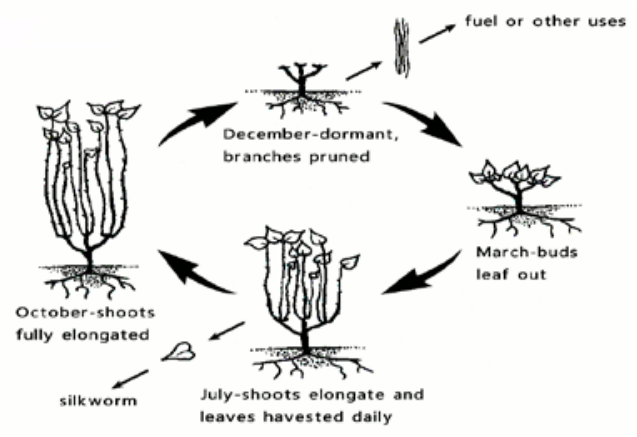

Figure 3. The standard cycle of mulberry management for sericulture in the region of China adjacent to the TGR. In winter (December) the trees are dormant and branches are pruned for uses such as fuel wood and mushroom cultivation. In March buds open and leaves emerge. In April farmers begin to gather leaves for silkworm cultivation and this continues daily through the summer, as indicated for July. In October shoot growth slows down at which time the elongated branches are bare except at their tips. Silkworm cultivation ceases in November prior to leaf fall.

\subsection{Reservoir Impoundment}

In 2008/9, following about 10 years of harvesting leaves from the plantation as described above, the TGR was impounded to $173 \mathrm{~m}$ above sea level for about a month and then lowered to about $170 \mathrm{~m}$, at which height it was held for about 3 months (Fig. 1). These elevations refer to the water height at the TGD. Lowering of the water level began in February 2009, reaching $145 \mathrm{~m}$ above sea level in May 2009. Since 2010, there have been annual cycles of water levels at about $175 \mathrm{~m}$ in winter and $145 \mathrm{~m}$ in summer, as shown in Figure 1. Flood pulses caused by monsoon rains have sometimes raised the water level in the TGR very significantly in summer, but have not inundated the upper $8 \mathrm{~m}$ of the drawdown zone at the Muhe location. Plants in the drawdown zone are subjected not only to annual winter 
flooding, and summer flooding in years when the Changjiang is in high spate, but also to occasional summer droughts during which temperatures remain above $35^{\circ} \mathrm{C}$ most of the time and may rise above $40^{\circ} \mathrm{C}$ each afternoon for extended periods of time when there is no rain.

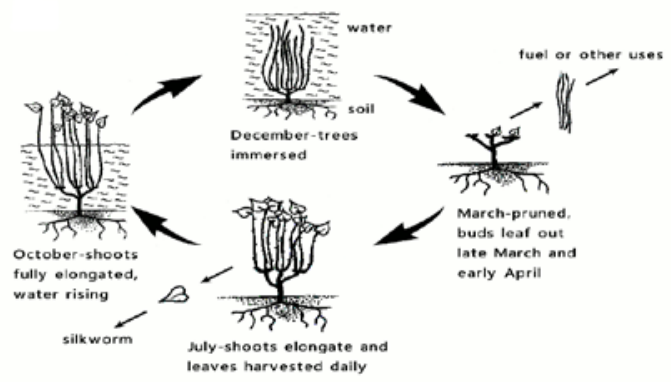

Figure 4. Modified cycle of mulberry management for sericulture in the TGR at Muhe village. In December pollards having long branches are immersed in water. Branches are pruned when the water is low enough in early March and buds begin to leaf out in late March. During the summer, branches grow and leaves are harvested for sericulture as usual. The water in the TGR rises in October and the plantation begins to be flooded (see Fig. 1 for actual timing of flooding).

\section{$2.3 \quad$ Mulberry Survival}

The local farmers initially reported in 2009 that mulberry trees flooded by up to $8 \mathrm{~m}$ of water for a prolonged period during the previous winter season had survived immersion. Surveys conducted by our group since these farmers' report have revealed that some mulberry pollards subjected to immersion in the drawdown zone have survived 7 consecutive years of winter flooding that partially immerses some of the trees and completely immerses others. Pollards with leaves sprouting in March 2013 lying on a terrace estimated to be at about $170 \mathrm{~m}$ above sea level are shown in Fig. 5. The depth of flooding is shown by the white mark of sediment deposited on the pole in the background which reached to at least $4.5 \mathrm{~m}$ above ground level. The marks on this and other poles were used to estimate the depth of flooding experienced by the pollards in the plantation, and a Geographic Positioning System device was used to estimate elevation above sea level. Other field indicators were also used to check flooding depth, such as the high water erosion line, line of mortality of flooding sensitive plants, and reports from farmers whose homes are immediately adjacent to the reservoir and plantation. Pollard stems that were almost completely immersed in October 2011, when the surface height of water at the TGD was about 170m above sea level (i.e. $5 \mathrm{~m}$ below its maximum height during that winter) are shown in Fig. 6. The maximum height of the pollards rarely exceeds $4 \mathrm{~m}$. The crowns of some of the trees are therefore below water during much of the winter period.

While there has been considerable mortality of trees on soil surfaces lying lower than $170 \mathrm{~m}$ above sea level (i.e. immersed under more than 5m of water), a few individual pollards had survived to 2013 on a terrace estimated to be at about $168 \mathrm{~m}$ above sea level, with crowns estimated to be at least $3 \mathrm{~m}$ below the water surface during the winter flood periods of 2010-2013. In addition to shoots emerging from scions, shoots have also been observed sprouting from buds lying below the soil surface arising from bases of rootstocks of immersed trees with damaged scions.

\subsection{Changes in Plantation Management}

The local farmers have altered their normal pollard management practice in order to adapt to the reservoir management regime (Fig. 4). While it is normal to conduct an annual cut of the sprouted branches in December each year, the farmers now leave these on the pollards until the water descends in February and March, and cut them as soon as they can access the trees. Pruned branches of 1.5 to 2.5 $\mathrm{m}$ in height which were coated with sediment from base to tip were observed to have living buds sprouting leaves and flowers on March 21st 2013. These had been removed from the trees and tied in bundles by the farmers in early March. 
Unexpectedly, in March 2013 living willow poles (probably Salix babylonica) were planted among many of the mulberry trees at this site (Fig. 5). The planting was conducted under the authority of the Three Gorges Corporation which owns usage rights for the reservoir drawdown zone.

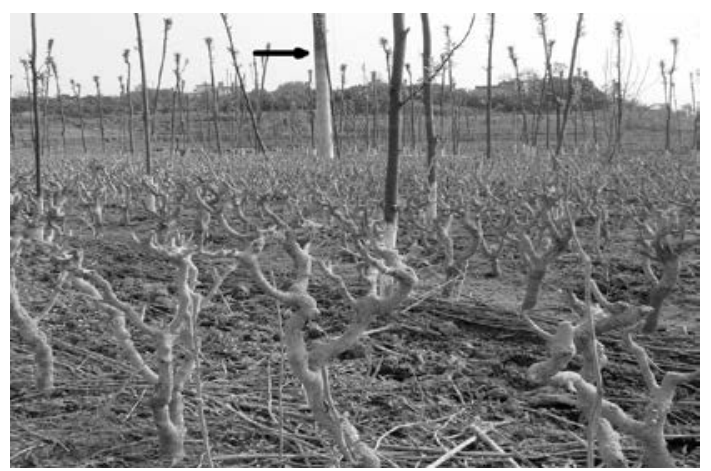

Figure5. Part of the mulberry plantation at Muhe Village on March 21, 2013. Sediment-coated mulberry pollards in the foreground were beginning to leaf out. Tall willow stems have white-painted bases, and a concrete utility pole in the background was coated with sediment up to the arrow, showing that at greatest depth the water was at least $4 \mathrm{~m}$ above the terrace during winter. The willow stems were planted after the water level had been lowered and were therefore not sediment-coated.

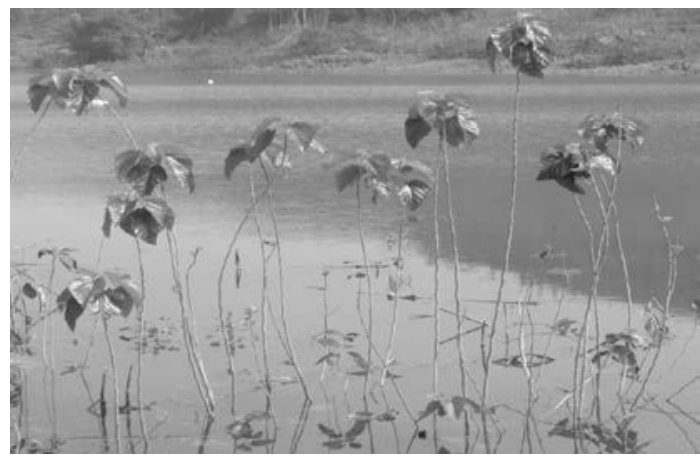

Figure 6. Mulberry trees partially immersed in the TGR at Muhe Village on October 9, 2011. Note that leaves are present only on the tips of branches, those lower down having been harvested for sericulture. The height of water height at TGD on 9-10-2011 was $170 \mathrm{~m}$ above sea level according to data at the TGD corporation website (see Fig. 1). The maximum heights of the water in the winters of $2010 / 11$ and $2011 / 12$ were therefore about $5 \mathrm{~m}$ higher than shown in this photograph.

\section{Discussion}

\subsection{Plant Stress}

When the water level in a reservoir is drawn down, the exposed bank is available for colonization by plants, but when the water level is raised again these plants are subjected to flooding. Plants are stressed in this environment, notably by anoxia, and very few woody perennial species are able to tolerate it [16], [17], [18].

When the level of water in the TGR recedes in March and April, dormant buds on pollards in the $M$. alba plantation described here have leafed out each year since 2008. We are aware of other locations where this phenomenon has also been observed, but details have not been published. There are several locally-adapted mulberry cultivars, as well as many differences in site conditions and methods of propagation. The ranges of tolerance related to these variables are not yet known. M. alba is a riparian species that is known to tolerate physiological stresses such as freezing, drought and water-logging [15], [19], [20], but it was not expected to survive the severe stress of long-term winter flooding to depths that 
cover the crown of the tree. Following observation of mulberry survival, new experimental plantations have been established recently in the TGR drawdown zone in Yunyang and Wanzhou (regions of Chongqing) and some young transplanted trees have survived for up to four annual cycles at submersion depths up to $7 \mathrm{~m}$ (authors' personal observations of unreported experiments).

\subsection{Reservoir Management}

Roughly $30 \%$ of the land in the TGR drawdown zone was terraced and farmed prior to creation of the TGR [6] and many farmers who now live adjacent to the reservoir remain interested in using the periodically exposed land if possible. This is a pressing issue for management of the TGR because hundreds of thousands of farmers were displaced by its creation. The land in the drawdown zone is government-owned and the land-use rights of the farmers were expunged, with compensation, on creation of the reservoir. For this reason, use of this land is regulated and compatible uses for it are being sought. This interest has created a demand for research on which crops and cropping systems might be compatible with the growing conditions in the drawdown zone, while not compromising other environmental objectives [6], [7], [8]. The use of fertilizers and pesticides in the drawdown zone is officially discouraged in order to protect reservoir water quality, but fertilizers and pesticides are not essential for mulberry cultivation. Sediments deposited during winter flooding deliver nutrients and some of these are then removed by harvesting the mulberry leaves, potentially reducing eutrophication of the reservoir. Insecticides are undesirable in mulberry cultivation because the crop is fed to an insect, the silkworm. Mulberry provides many benefits to farmers, not only for sericulture but also as fodder for livestock (goats, cows and chickens). The full range of benefits and limitations of this agronomic system therefore require further researches in order to assess its full potential.

In addition to providing economic returns with few inputs for farmers, plantations of mulberry may be valuable for stabilizing soils in the drawdown zone because the root system of the tree is very extensive both horizontally and vertically [14], [19]. Slumping of moderately-sloping soils is a problem in all reservoirs [1]. Around the TGR such slopes were mostly terraced for farming but the terraces are tending to collapse as the water level rises and falls through the annual reservoir management cycle. The terraces at this site appear to be relatively stable (see Fig. 5) while nearby sloping lands appear to have been eroded to a greater extent (personal observations). It seems probable that soils at this site have been stabilized by the extensive root systems of $M$. alba, but further field observations and experiments are required to verify this hypothesis. In addition to stabilizing soils, mulberry roots coated with mycorrhizae sequester heavy metal pollutants [21], which is a potentially valuable attribute in the TGR [11].

Several studies have focused on how to address the environmental damage in the TGR through actions, such as environmental engineering [7], [8], using approaches that have been successful elsewhere in the world when similar problems associated with large dams and reservoirs have had to be confronted [1]. Nevertheless, in every region of the world there are unique conditions that require regionally unique responses. Here we have described a specific case of local observations of an unpredicted natural phenomenon that may provide a valuable way to address several of the environmental problems associated with the TGR. Growing woody vegetation in the drawdown can provide benefits such as stabilizing soils, absorbing nutrient pollution, sequestering carbon, beautifying the landscape, providing commercial resources, and creating foundations for biodiversity. While there cannot be any single panacea for all the environmental ills of such a large project, the approach illustrated here of taking account of local farmers' knowledge of distinctly local vegetative conditions is illuminating.

While it is clear that pre-established $M$. alba can tolerate flooding in the TGR, the species will not necessarily survive nor be adopted for use unless the entire system is adequately understood. Experimentation will be required to understand the biological, environmental and economic variables of the system: the relative flood tolerance of mulberry varieties; the roles played by plant management systems and soil conditions; mulberry survival relative to inundation depth, timing of submersion and leafing out; volume and market values of products, and the acceptability of growing mulberry in the drawdown for farmers and government. It is likely that more land is potentially available than the market for current products can bear, and therefore research may also expand to include developing a wider range of products that can be obtained from mulberry trees without compromising the environmental services they provide in stabilizing the soils of the reservoir banks and removing inorganic 
pollutants from the reservoir water. In this regard, $M$. alba grown as standard trees in urban and suburban settings may be very useful [22].

Bald cypress ( Taxodium distichum) also survives inundation well and provides valuable wood [8], [10], but it is not native to China. A planting strategy for the drawdown zone that optimizes ecological services, provides for the economic needs of local farmers, and focuses on native vegetation, is likely to include several flood-tolerant woody species that are familiar to local people but less familiar to environmental scientists outside China, such as the shrub Distylium sinense [23] and the tree Pterocarya stenoptera [10], [24].

The plantation described here lies about $480 \mathrm{~km}$ upstream from the TGD in a channel that is separated from the river's main stem by an island (Fig. 2). The channel is not a transportation corridor due to its shallow depth and variable contours. Prior to filling of the reservoir, all trees in the future drawdown zone of the reservoir were ordered to be removed because they were a potential shipping hazard, but smaller trees which had no potential to interfere with navigation were sometimes left alone, as in this case. Nevertheless, management of the entire drawdown zone is controlled by the Three Gorges Corporation for its purposes, which include environmental protection. Sequestering nutrients from polluted water is one of these ecological objectives, and this is generally the rationale for planting trees in the drawdown at sites which do not conflict with the corporation's other objectives, willows in this case (Fig. 5). While this objective is rational, it is unclear why a site that already had this ecological function would have been selected when many other similar sites which lack perennial woody vegetation are available in the TGR drawdown zone. Had the management plan been more adaptive and more consultative at the community level, including social learning approaches [25], [26], a different decision might have been made, one that better integrated the interests of local people and provided a more sustainable outcome [27], [28]. We recommend that the reservoir management regime be more adaptive and that community consultation be improved in order to obtain effective outcomes at lower economic and social costs. Nevertheless, the modified site itself remains very useful in an experimental context and should continue to be monitored and evaluated with respect to tree survival, provision of ecosystem services, sustainable agricultural practices, and economic benefits to the local community.

Acknowledgements. This work was supported by grant No. 31370602 from the National Natural Science Foundation of China. We are very grateful to the farmer, Zongming Zhou, who initially brought the survival of this plantation to our attention and whose family has maintained the plantation for many years. He and his family provided valuable information about the site described here. We are also very grateful to Xianzhi Huang for permission to use the photograph in Fig. 6. We thank Xingzheng Xiong for preparing Fig. 1 from data available to the public in China. We thank Fangminan Feng for transforming the hand-drawn graphics in Figs. 3 and 4 into digital form.

\section{References}

1. R.M. Baxter, "Environmental effects of dams and impoundments," Annual Review of Ecology and Systematics, vol. 8, pp. 255-283, 1981.

2. J.N. Pretty, J.I.L. Morison, and R.E. Hine, "Reducing food poverty by increasing agricultural sustainability in developing countries," Agriculture Ecosystems and Environment, vol. 95, pp. 217-234, 2003.

3. R. Stone, "Three Gorges Dam: into the unknown," Science, vol. 321, pp. 628-632, 2008.

4. B-J. Fu, B-F. Wu, Y-H. Lü, Z-H. Xu, J-H. Cao, D. Niu, G-S. Yang and Y-M. Zhou, "Three Gorges project: efforts and challenges for the environment," Progress in Physical Geography, vol. 34, pp. 741-754, 2010.

5. X-B.Xu, Y. Tan, G. Yang, H-P Li and W-Z Su, "Impacts of China's Three Gorges Dam Project on net primary productivity in the reservoir area," Science of the Total Environment, vol. 409, pp. 4656-4662, 2011.

6. Q. Zhang, and Z-P. Lou, "The environmental changes and mitigation actions in the Three Gorges reservoir region, China," Environmental Science and Policy, vol. 14, no. 8, pp.1132-1138, 2011.

7. J.H.M. Willison, R-X. Li, and X-Z. Yuan, "Conservation and eco-friendly utilization of wetlands associated with the Three Gorges Reservoir," Environmental Science and Pollution Research, vol. 20, no. 10, pp. 6907-6916, 2013. 
8. X-Z. Yuan, Y-W. Zhang, H. Liu, X. Sen, B. Li and W. Deng, "The littoral zone in the Three Gorges Reservoir, China: challenges and opportunities," Environmental Science and Pollution Research, vol. 20, no. 10, pp. 7092$7102,2013$.

9. K-F. Li, C. Zhu, L. Wu and L-Y. Huang, "Problems caused by the Three Gorges Dam construction in the Yangtze River basin: a review," Environmental Reviews, vol. 21, pp.127-135, 2013.

10.F. Yang, Y. Wang and Z-L. Chan, "Perspectives on screening winter-flood-tolerant woody species in the riparian protection forests of the Three Gorges Reservoir," PLoS ONE, vol. 9, no. 9, e108725, 2014.

11.Y. Liu, J.H.M. Willison, P. Wan, X-Z. Xiong, Y. Ou, X-H. Huang, J-C. Wu, H. Zhou, Q. Xu, G-H. Chen, Y-Z. Xili, J-S. Nie, "Mulberry trees conserved soil and protected water quality in the riparian zone of the Three Gorges Reservoir, China," Environmental Science and Pollution Research, vol. 23, no. 6, pp. 5288-5295, 2016.

12.Y. Wang, M. Liao, G. Sun and J. Gong, "Analysis of the water volume, length, total area and inundated area of the three Gorges reservoir, China using the SRTM DEM data," International Journal of Remote Sensing, vol. 26, pp. 4001-4012, 2005.

13.Q. Wang, X-Z. Yuan, J.H.M. Willison, Y-W. Zhang and H. Liu, "Diversity and above-ground biomass patterns of vascular flora induced by flooding in the drawdown area of China's Three Gorges Reservoir," PLoS ONE, vol. 9, No. 6, e100889, 2014.

14.X-B. He, Z-Q. Xie, H-W. Nan and Y-H. Bao, "Developing ecological economy of sericulture and vegetation restoration the water-level-fluctuating zone of the Three Gorges Reservoir," Science and Technology Review, vol. 25, No. 23, pp. 59-63, 2007. (in Chinese)

15.Y. Liu, and J.H.M. Willison, "Prospects for cultivating white mulberry (Morus alba) in the drawdown zone of the Three Gorges Reservoir, China," Environmental Science and Pollution Research, vol. 20, pp. 7142-7151, 2013.

16.R.M.M. Crawford, Studies in Plant Survival. Blackwell Scientific Publications, Oxford, UK, 1989.

17.B.B. Vartapetian, and M.B. Jackson, "Plant adaptations to anaerobic stress," Annals of Botany 79 (Suppl. A), pp. 3-20, 1997.

18.M.B. Jackson, and T.D. Colmer, "Response and adaptation by plants to flooding stress," Annals of Botany vol. 96, pp. 501-505, 2005.

19.Y. Liu, "Application prospect of mulberry plants to vegetation restoration in the Three Gorges Reservoir Area," Science of Sericulture vol. 37, No. 1, pp. 93-97, 2011. (in Chinese)

20.X-H. Huang, Y. Liu, J-X. Li, X-Z. Xiong, Y. Chen, X-H. Yin, and D-L. Feng, "The response of mulberry trees after seedling hardening to summer drought in the hydrofluctuation belt of the Three Gorges Reservoir Area," Environmental Science and Pollution Research, vol. 20, no. 10, pp. 7103-7111, 2013.

21.Y-H. Fan, H-W. Ling, and H-C. Piao, "Effects of symbiosis of mulberry (Morus alba) with arbuscular mycorrhizae on absorption of heavy metals (Fe, Mn, Zn, Cu and $\mathrm{Cd}$ )," Ecology and Environmental Sciences, vol. 23, no. 3, pp. 477-484, 2014. (in Chinese).

22.J. Qin, N-J. He, X-Z. Huang, Z-H Xiang, "Development of mulberry ecological industry and sericulture," Science of Sericulture, vol. 36, no. 6, pp. 984-989, 2010. (in Chinese)

23.Liu, R. Cheng, W. Xiao, Q. Guo, and N. Wang, "Effect of off-season flooding on growth, photosynthesis, carbohydrate partitioning, and nutrient uptake in Distylium chinense," PLoS ONE vol. 9, no. 9, e107636, 2014.

24.X-D. Xian,Y-L Feng, J.H.M. Willison, L-J Ai, P. Wang, Z-N Wu, "Restoring ecosystem services to littoral zones of rivers in the urban core of Chongqing, China," Environmental Science and Pollution Research, vol. 22, no. 16, pp. 12576-12584, 2015.

25.E. Mostert, C. Pahl-Wostl, Y. Reese, B. Searle, D. Tabara, and J. Tippett, "Social learning in European river basin management: barriers and fostering mechanisms from 10 river basins," Ecology and Society vol. 12, no. 1, article 19, 2007.

26.C. Pahl-Wostl, D. Tabara, R. Bouwen, M. Craps, A. Dewulf, E. Mostert, D. Ridder, and T. Taillieu. 2008. The importance of social learning and culture for sustainable water management. Ecological Economics vol. 64, pp. 484-495, 2008.

27.R.D. Margerum, "Integrated environmental management: the foundations for successful practice," Environmental Management, vol. 24, no. 2, pp.151-166, 1999.

28.M.S. Reed, "Stakeholder participation for environmental management: a literature review," Biological Conservation vol. 141, no. 10, pp. 2417-2431, 2008. 